PREPARED FOR THE U.S. DEPARTMENT OF ENERGY, UNDER CONTRACT DE-AC02-76CH03073

PPPL-3716

PPPL-3716

UC-70

\title{
Recent Progress \\ on the National Spherical Torus Experiment
}

by

D.A. Gates, M.G. Bell, R.E. Bell, J. Bialek, T.Bigelow,

M. Bitter, P. Bonoli, D. Darrow, P. Efthimion, J. Ferron,

E. Fredrickson, L. Grisham, J. Hosea,

D. Johnson, R. Kaita, et al.

July 2002
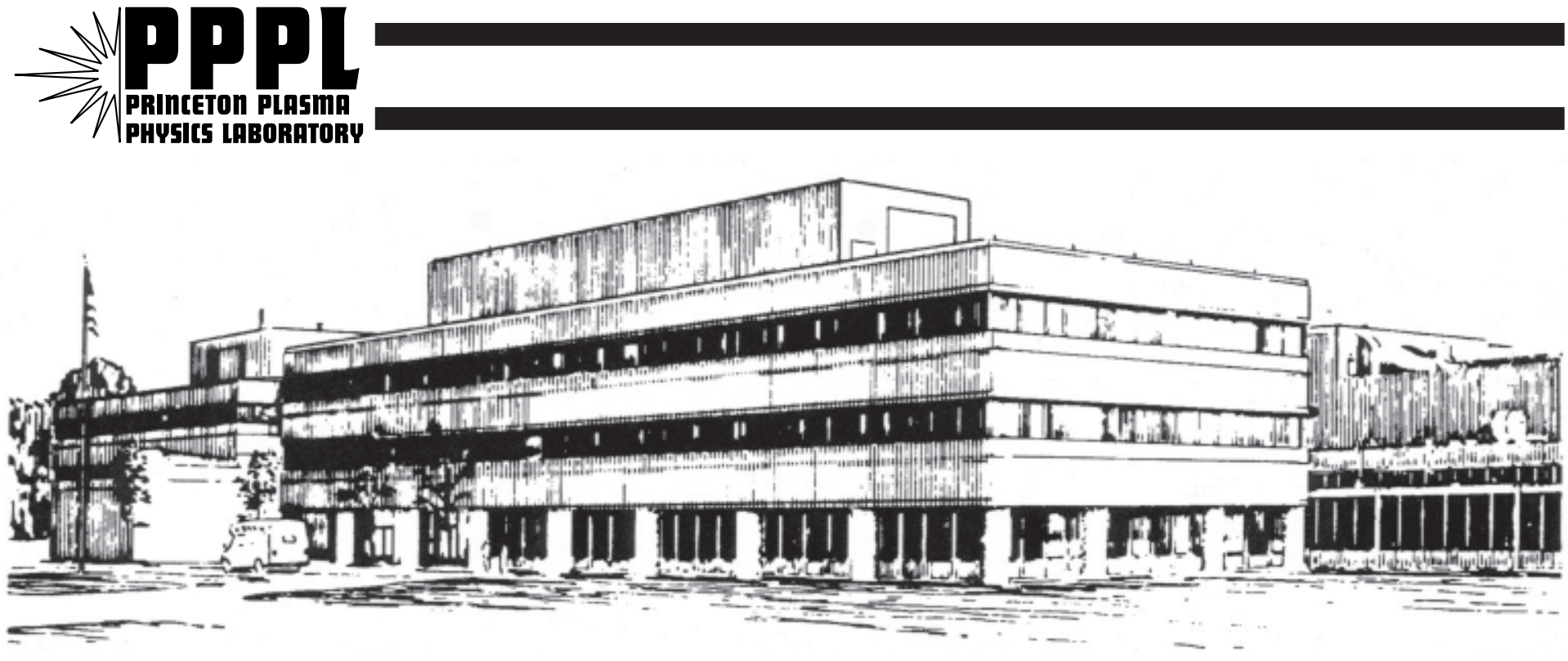

PRINCETON PLASMA PHYSICS LABORATORY PRINCETON UNIVERSITY, PRINCETON, NEW JERSEY 


\section{PPPL Reports Disclaimer}

This report was prepared as an account of work sponsored by an agency of the United States Government. Neither the United States Government nor any agency thereof, nor any of their employees, makes any warranty, express or implied, or assumes any legal liability or responsibility for the accuracy, completeness, or usefulness of any information, apparatus, product, or process disclosed, or represents that its use would not infringe privately owned rights. Reference herein to any specific commercial product, process, or service by trade name, trademark, manufacturer, or otherwise, does not necessarily constitute or imply its endorsement, recommendation, or favoring by the United States Government or any agency thereof. The views and opinions of authors expressed herein do not necessarily state or reflect those of the United States Government or any agency thereof.

\section{Availability}

This report is posted on the U.S. Department of Energy's Princeton Plasma Physics Laboratory Publications and Reports web site in Fiscal Year 2002. The home page for PPPL Reports and Publications is: http://www.pppl.gov/pub_report/

DOE and DOE Contractors can obtain copies of this report from:

U.S. Department of Energy

Office of Scientific and Technical Information

DOE Technical Information Services (DTIS)

P.O. Box 62

Oak Ridge, TN 37831

Telephone: (865) 576-8401

Fax: (865) 576-5728

Email: reports@adonis.osti.gov

This report is available to the general public from:

National Technical Information Service

U.S. Department of Commerce

5285 Port Royal Road

Springfield, VA 22161

Telephone: 1-800-553-6847 or

(703) 605-6000

Fax: (703) 321-8547

Internet: http://www.ntis.gov/ordering.htm 


\title{
Recent progress on the National Spherical Torus Experiment (NSTX)*
}

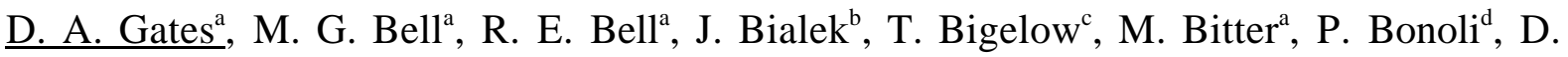
Darrow $^{\mathrm{a}}$, P. Efthimion ${ }^{\mathrm{a}}$, J. Ferron ${ }^{\mathrm{e}}$, E. Fredrickson ${ }^{\mathrm{a}}$, L. Grisham ${ }^{\mathrm{a}}$, J. Hosea ${ }^{\mathrm{a}}$, D. Johnson ${ }^{\mathrm{a}}$, R. Kaita $^{\mathrm{a}}$, S. Kaye ${ }^{\mathrm{a}}$, S. Kubota ${ }^{\mathrm{f}}$, H. Kugel ${ }^{\mathrm{a}}$, B. LeBlanc ${ }^{\mathrm{a}}$, R. Maingi ${ }^{\mathrm{c}}$, J. Manickam $^{\mathrm{a}}$, T. K. Mau ${ }^{\mathrm{g}}$, R. J. Maqueda ${ }^{\text {h, E. Mazzucato }}{ }^{\mathrm{a}}$, S. S. Medley ${ }^{\mathrm{a}}$, J. Menard $^{\mathrm{a}}$, D. Mueller ${ }^{\mathrm{a}}$, B. Nelson ${ }^{\mathrm{i}}$, N. Nishino $^{\mathrm{j}}$, M. Ono ${ }^{\mathrm{a}}$, F. Paoletti ${ }^{\mathrm{b}}$, S. Paul ${ }^{\mathrm{a}}$, Y-K. M. Peng ${ }^{\mathrm{c}}$, C. K. Phillips ${ }^{\mathrm{a}}$, R. Raman ${ }^{\mathrm{i}}$, M. H. Redi $^{\mathrm{a}}$, A. L. Rosenberg ${ }^{\mathrm{a}}$, P. Ryan ${ }^{\mathrm{c}}$, S. A. Sabbagh ${ }^{\mathrm{b}}$, M. Schaffer ${ }^{\mathrm{e}}$, C. H. Skinner ${ }^{\mathrm{a}}$, V. Soukhanovskii $^{a}$, D. Stutman ${ }^{k}$, D. Swain ${ }^{c}$, E. Synakowski ${ }^{a}$, Y. Takase ${ }^{1}$ J. Wilgen ${ }^{c}$, J.R. Wilson $^{\mathrm{a}}$, W. Zhu ${ }^{\mathrm{b}}$, S. Zweben ${ }^{\mathrm{a}}$, A. Bers ${ }^{\mathrm{d}}$, R.V. Budny ${ }^{\mathrm{a}}$, M. Carter ${ }^{\mathrm{c}}$, B. Deng ${ }^{\mathrm{m}}$, C. Domier ${ }^{\mathrm{m}}$, E.

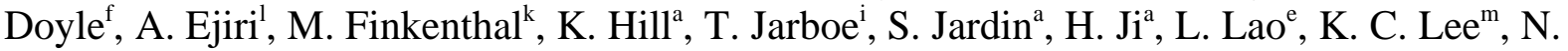
Luhmann $^{\mathrm{m}}$, R. Majeski ${ }^{\mathrm{a}}$, O. Mitarai ${ }^{\mathrm{p}}$, M. Nagata ${ }^{\mathrm{q}}$, Y. Ono ${ }^{1}$, H. Park ${ }^{\mathrm{a}}$, T. Peebles ${ }^{\mathrm{f}}$, R. I. Pinsker $^{\mathrm{e}}$, G. Porter ${ }^{\mathrm{n}}$, A. Ram ${ }^{\mathrm{d}}$, M. Rensink ${ }^{\mathrm{n}}$, T. Rognlien ${ }^{\mathrm{n}}$, S. Shiraiwal, D. Stotler ${ }^{\mathrm{a}}$, B.

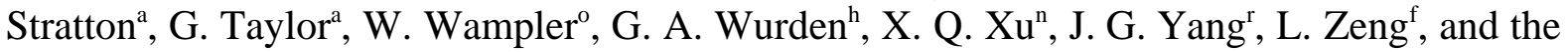
NSTX Team

${ }^{a}$ Princeton Plasma Physics Laboratory, Princeton University, Princeton, N.J. 08543

${ }^{b}$ Dept. of Applied Physics, Columbia Univ., NYC, N.Y.

' Oak Ridge National Laboratory, Oak Ridge, Tenn.

${ }^{d}$ MIT, Cambridge, Mass.

${ }^{e}$ General Atomics, San Diego, Cal.

${ }^{f}$ UCLA, Los Angeles, Cal.

${ }^{g}$ UC-San Diego, San Diego, Cal.

${ }^{h}$ Los Alamos National Laboratory, Los Alamos, N.M.

${ }^{i}$ Univ. of Washington, Seattle, Wash.

${ }^{j}$ Hiroshima Univ., Hiroshima, Japan

${ }^{k}$ Johns Hopkins University, Baltimore, Md.

${ }^{\prime}$ Univ. of Tokyo, Tokyo, Japan

${ }^{m}$ UC Davis, Davis, Cal.

${ }^{n}$ Lawrence Livermore National Laboratory, Livermore, Cal.

${ }^{\circ}$ Sandia National Laboratory, Albuquerque, N.M.

${ }^{p}$ Kyushu Tokai Univ., Kumamoto, Japan

${ }^{q}$ Himeji Inst. Technology, Hyogo, Japan

${ }^{r}$ Korea Basic Science Institute, Taejeon, Korea

\begin{abstract}
Recent upgrades to the NSTX facility have led to improved plasma performance. Using $5 \mathrm{MW}$ of neutral beam injection, plasmas with toroidal $\beta_{\mathrm{T}}\left(=2 \mu_{0}\langle\mathrm{p}\rangle / \mathrm{B}_{\mathrm{T}}^{2}\right.$ where $\mathrm{B}_{\mathrm{T}}$ is the vacuum toroidal field at the plasma geometric center) $>30 \%$ have been achieved with normalized $\beta_{\mathrm{N}}\left(=\beta_{\mathrm{T}} \mathrm{BB}_{\mathrm{I}} / \mathrm{I}_{\mathrm{p}}\right) \approx 6 \% \cdot \mathrm{m} \cdot \mathrm{T} / \mathrm{MA}$. The highest $\beta$ discharge exceeded the calculated no-wall $\beta$ limit for several wall times. The stored energy has reached $390 \mathrm{~kJ}$ at higher toroidal field $(0.55 \mathrm{~T})$ corresponding to $\beta_{\mathrm{T}} \approx 20 \%$ and $\beta_{\mathrm{N}}=5.4$. Long pulse $(\sim 1 \mathrm{~s})$ high $\beta_{p}(\sim 1.5)$ discharges have also been obtained at higher $B_{\phi}(0.5 \mathrm{~T})$ with up to $6 \mathrm{MW}$ NBI power. The highest energy confinement times, up to $120 \mathrm{~ms}$, were observed during $\mathrm{H}$-mode operation which is now routine. Confinement times of $\sim 1.5$ times ITER98pby 2 for several $\tau_{E}$ are observed during both H-Mode and non-H-Mode discharges. Calculations indicate that many NSTX discharges have very good ion confinement, approaching neoclassical levels. High Harmonic Fast Wave current drive has been demonstrated by comparing discharges with waves launched parallel and anti-parallel to the plasma current.
\end{abstract}

\section{Machine improvements}

Several improvements to the NSTX facility have improved plasma performance. In particular, $350^{\circ} \mathrm{C}$ bakeout capability, along with the addition of a gas fuelling port on the high field side of the plasma, has improved access to the H-mode. In addition, the realignment of one of the poloidal field coils has reduced the non-axisymmetric error fields in 
the plasma region and decreased the occurrence of locked modes that were observed in the first NSTX physics campaign [1]. These improvements have led to a large expansion of the operational regime on NSTX.

High $\beta$

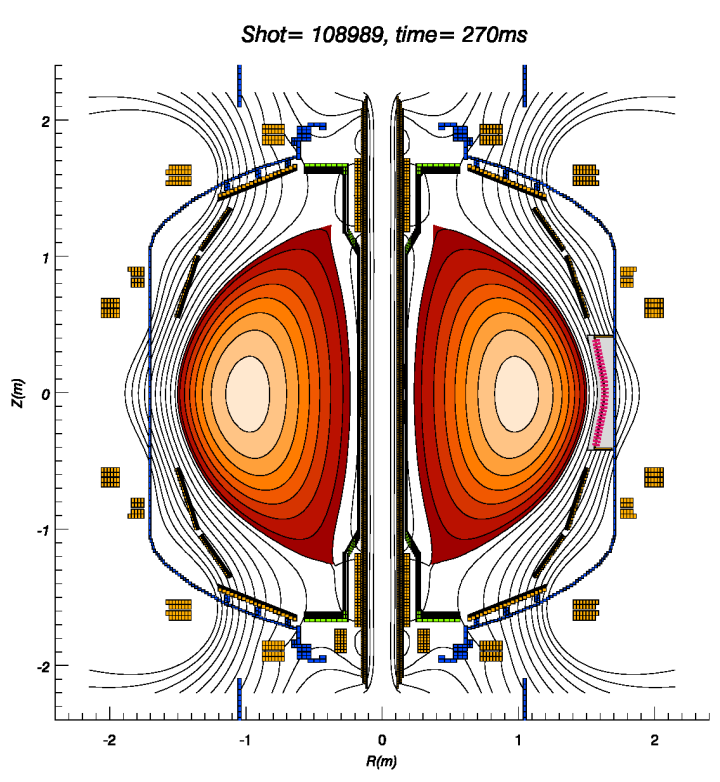

Figure 1 Equilbrium flux plot for shot 108989 $\beta_{T}=34 \%, I_{p}=1.2 M A, B_{T}=0.3 T e s l a$

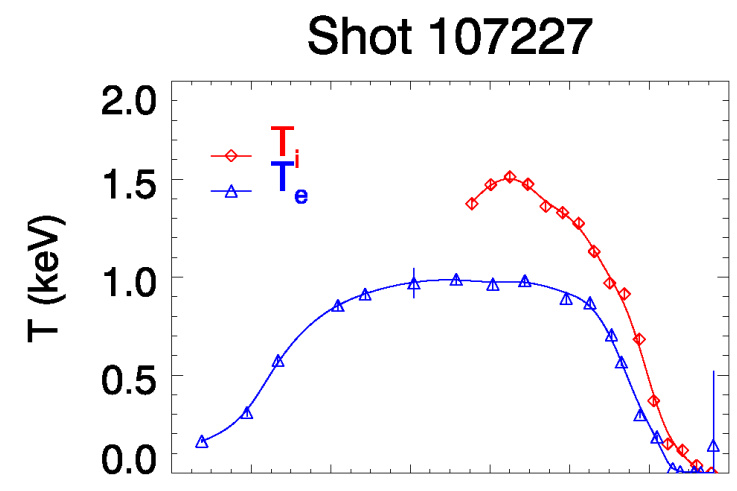

$20 \quad 40 \quad 60 \quad 80100120140160$ Radius (cm)

NSTX has achieved very high values of toroidal $\beta_{T} \sim 34 \%$, similar to those achieved on the START device $[2,3]$. The highest $\beta$ 's were achieved in a high triangularity double null configuration with modest elongation $\kappa \sim 1.8$. A high $\beta$ equilibrium reconstruction [4], from shot 108989, is shown in Figure 1. The stabilizing effect of high triangularity is amplified at low aspect ratio, due to the strong variation of the toroidal field. High triangularity double null discharges at higher toroidal field and plasma current have also led to the highest stored energies $(0.4 \mathrm{MJ})$ achieved to date on NSTX.

Figure 2 shows the measured kinetic profiles for shot 107227 close to the time of peak $\beta$. The ion temperature is measured using charge-exchange recombination spectroscopy, and the electron density and temperature are

Shot 107227

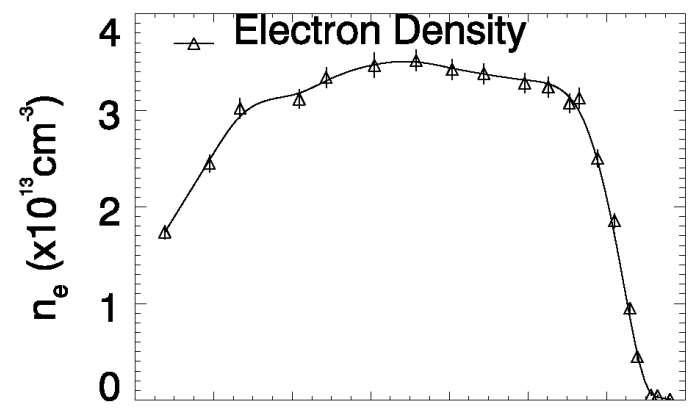

\section{$20 \quad 40 \quad 60 \quad 80100120140160$ \\ Radius (cm)}

Figure 2 Kinetic profiles for shot 107227, $\beta=32 \%, I_{p}=1.2 M A, B_{T}=0.3$ Tesla

measured using Thomson scattering. In general on NSTX, total stored energy calculated using the TRANSP code agrees well with the value obtained from magnetic reconstructions.

\section{$\beta$ limiting instabilities}

Figure 3 shows the time evolution of the MHD stability parameter $\delta \mathrm{W}$ calculated by the DCON ideal stability code [5]. These results indicate that $\beta$ exceeded the no-wall $\beta$-limit for approximately 10 wall penetration times. This indicates that either the plasma rotation speed is sufficiently high to cause the conducting structure to stabilize the calculated instability, or alternatively that the mode is being stabilized directly by rotational shear.

In plasmas that are closely coupled to the conducting structure in NSTX, non-rotating modes, identified as resistive wall modes [6], can limit $\beta$. The onset of these modes is preceded by the characteristic slowdown in plasma rotation. 
For plasmas with $\mathrm{q}(0) \sim 1$, neoclassical tearing modes are observed to limit $\beta$. These modes are slowly growing and, in many shots, are identified to be $3 / 2$ islands. The mode growth is consistent with that predicted by the modified Rutherford equation. These modes are most easily avoided by operating plasmas with elevated $\mathrm{q}(0)$.

\section{Long pulse high $\beta_{p}$}

Long pulse plasmas with very low loop voltage have been created on NSTX. These discharges typically operate at lower values of normalized current $I_{N}(=I / a B) \sim 3 M A / m \bullet T$ to avoid ideal MHD instabilities, while raising $\beta_{p}$. The combined bootstrap and beamdriven current for these discharges is calculated by TRANSP to be up to $\sim 50 \%$. This is an important

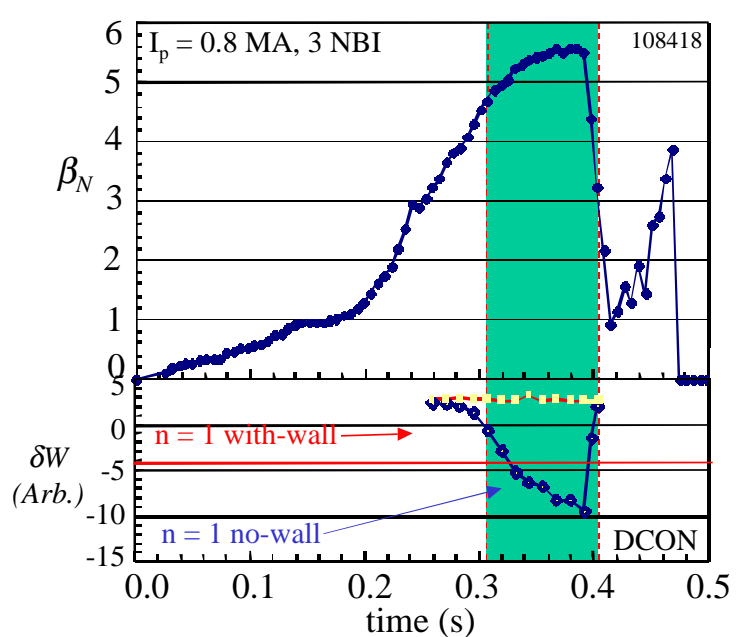

Figure 3 The MHD stability parameter $\delta W v$ s. time as calculated by the DCON ideal stability code achievement, since ST reactor concepts rely heavily on non-inductive current drive to overcome the difficulties of installing a transformer in the slender center column of such devices.

These plasmas are exclusively operated in the H-mode, which is crucial for obtaining the broad pressure profiles that are required to operate at elevated values of $\beta_{N}$. Typically these plasmas are formed as lower single null divertors, due to the improved access to the $\mathrm{H}$ mode. Pressure peaking factors $(\mathrm{p}(0) /\langle\mathrm{p}\rangle)$ as low as 1.9 have been measured during extended

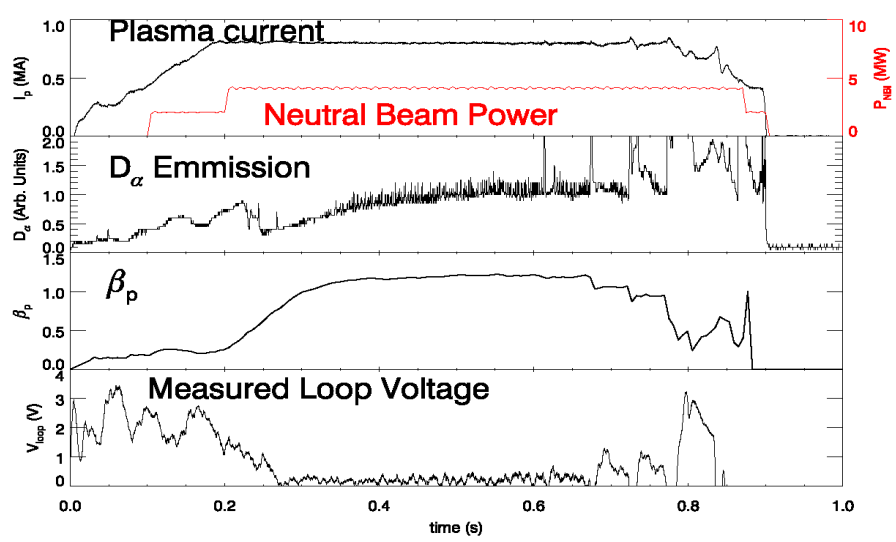

Figure 4 Discharge evolution for shot 108731, a high $\beta_{p}$ long pulse discharge with reduced loop voltage
ELM-free H-modes on NSTX. Figure 4 shows a typical discharge evolution for such a discharge.

\section{Transport}

Confinement in NSTX beam heated discharges is usually above that predicted by tokamak scaling laws. Global confinement time $\mathrm{H}$ factors, compared to ITER98pby2, are typically $\mathrm{H} \sim 1.5$, lasting for several $\tau_{E}$. Interestingly, this improved confinement seems independent of whether the plasmas are operated with H-mode or L-mode edges.

The usual situation in NSTX beam heated discharges is that the ion thermal conductivity calculated by TRANSP with standard assumptions for beam thermalization and power balance is very low or even negative. The cause of this mystery is still under investigation. One intriguing possibility is anomalous heating of thermal ions by beam ions [7]. Heating of ions by turbulence associated with the electron temperature gradient instability or by neoclassical heat pinches have been suggested as other potential explanations.

Particle diffusivity has been inferred from the evolution of the soft x-ray emission profile following neon impurity puffing[8]. The core neon diffusivity is on the order of that 
predicted from neoclassical theory. The diffusivity was modeled using the MIST [9] atomic physics code.

\section{Radio frequency heating and current drive}

High Harmonic Fast Wave (HHFW) heating by RF waves at $30 \mathrm{MHz}\left(10-30 \times f_{\text {ci }}\right)$

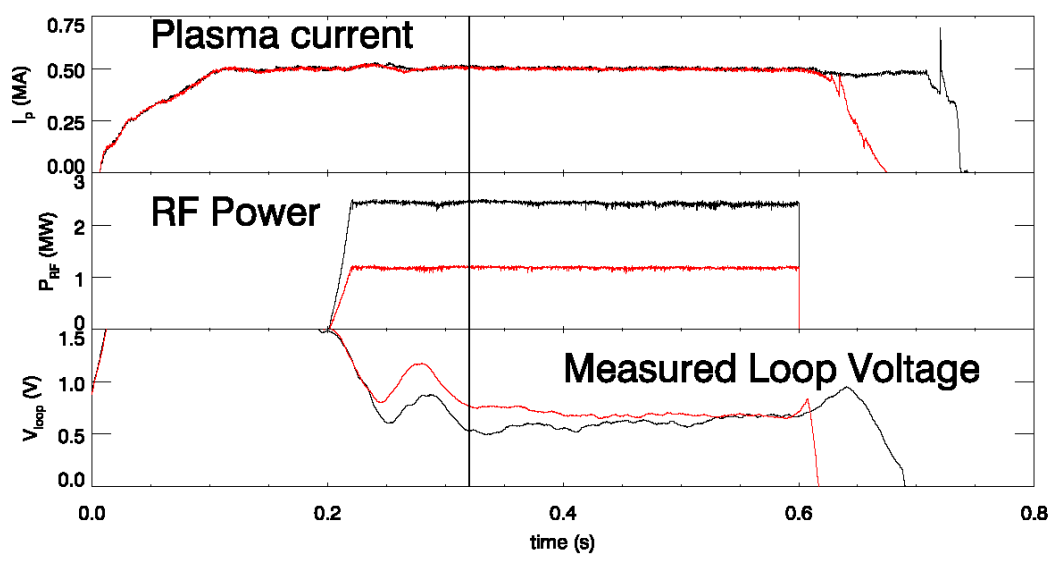

Figure 5 Co-counter current drive comparison using High Harmonic Fast waves $($ Co $=$ black, Counter $=$ red $)$ has been demonstrated previously on NSTX [10]. Recent experiments have also demonstrated substantial HHFW current drive 11 . Figure 5 shows the measured loop voltage for two plasma discharges for which the phasing of the 12strap antenna system was varied to launch waves with phase velocity either parallel (co-) or anti-parallel (counter-) to the plasma current. The co-current

phasing shows a substantially reduced loop voltage relative to the counter-current drive case. The electron temperature and density are well matched between the two cases. The apparent loss of current drive is caused by an increase in the temperature of the counter current drive case over time.

\section{Summary}

NSTX has led the ST concept into new parameter regimes by achieving both high $\beta$ and good confinement. The stored energy has reached $0.4 \mathrm{MJ}$ with $7 \mathrm{MW}$ of injected neutral beam power at a plasma current of 1.5MA. The ideal no-wall $\beta$ limit has been exceeded for many wall times, but has not exceeded the calculated ideal wall limit. Toroidal $\beta_{T}$ has reached $34 \%$, and poloidal $\beta_{p} \approx 1.5$ has been produced. The high $\beta_{p}$ discharges had a high bootstrap and beam driven current fraction. The confinement on NSTX often substantially exceeds the predictions of tokamak scaling laws with $\mathrm{H}_{89 \mathrm{p}} \sim 2.5-3$ and $\mathrm{H}_{98 \mathrm{pby} 2} \sim 1.5$. The ion confinement is particularly good on NSTX, and in many cases the ion temperature exceeds the predictions of classical beam heating. These results indicate that many of the predicted advantages of low aspect ratio are have been realized.

* Work supported by U.S. DOE Contract DE-AC02-76CH03073

1 J. Menard, et al., to be submitted to Nuclear Fusion (2002)

2 D. Gates, et al., Phys. Plasmas 5, (1998) 1775

3 M. Gryaznevich, et al., Phys. Rev. Lett. 80, (1998) 3972

4 S. A. Sabbagh, S. M. Kaye, J. Menard, et al., Nucl. Fusion 41, (2001) 1601.

5 A. H. Glasser and M. S. Chance, Bull Am. Phys. Soc. 42, (1997) 1848

6 S. A. Sabbagh, R. E. Bell, M. G. Bell, et al., Phys. Plasmas 9, (2002) 2085

7 D. A. Gates, N. N. Gorelenkov, R. B. White, Phys. Rev. Lett. 87, (2001) 205003-1

8 D. Stutman, et al., This conference

9 R.A. Hulse, Nuclear Technology/Science 3, 259 (1983)

10 S. Kaye, et al., Phys. Plasmas 8, (2001) 1977

11 D. Swain, et al., this conference 


\section{External Distribution}

Plasma Research Laboratory, Australian National University, Australia

Professor I.R. J ones, Flinders University, Australia

Professor J oão Canalle, Instituto de Fisica DEQ/IF - UERJ , Brazil

Mr. Gerson O. Ludwig, Instituto Nacional de Pesquisas, Brazil

Dr. P.H. Sakanaka, Instituto Fisica, Brazil

The Librarian, Culham Laboratory, England

Library, R61, Rutherford Appleton Laboratory, England

Mrs. S.A. Hutchinson, JET Library, England

Professor M.N. Bussac, Ecole Polytechnique, France

Librarian, Max-Planck-Institut für Plasmaphysik, Germany

J olan Moldvai, Reports Library, MTA KFKI-ATKI, Hungary

Dr. P. Kaw, Institute for Plasma Research, India

Ms. P.J . Pathak, Librarian, Insitute for Plasma Research, India

Ms. Clelia De Palo, Associazione EURATOM-ENEA, I taly

Dr. G. Grosso, Instituto di Fisica del Plasma, Italy

Librarian, Naka Fusion Research Establishment, J AERI, J apan

Library, Plasma Physics Laboratory, Kyoto University, J apan

Research Information Center, National Institute for Fusion Science, J apan

Dr. O. Mitarai, Kyushu Tokai University, J apan

Library, Academia Sinica, Institute of Plasma Physics, People's Republic of China

Shih-Tung Tsai, Institute of Physics, Chinese Academy of Sciences, People's Republic of China

Dr. S. Mirnov, TRINITI, Troitsk, Russian Federation, Russia

Dr. V.S. Strelkov, Kurchatov Institute, Russian Federation, Russia

Professor Peter Lukac, Katedra Fyziky Plazmy MFF UK, Mlynska dolina F-2, Komenskeho Univerzita, SK-842 15 Bratislava, Slovakia

Dr. G.S. Lee, Korea Basic Science Institute, South Korea

Mr. Dennis Bruggink, Fusion Library, University of Wisconsin, USA

Institute for Plasma Research, University of Maryland, USA

Librarian, Fusion Energy Division, Oak Ridge National Laboratory, USA

Librarian, Institute of Fusion Studies, University of Texas, USA

Librarian, Magnetic Fusion Program, Lawrence Livermore National Laboratory, USA

Library, General Atomics, USA

Plasma Physics Group, Fusion Energy Research Program, University of California at San Diego, USA

Plasma Physics Library, Columbia University, USA

Alkesh Punjabi, Center for Fusion Research and Training, Hampton University, USA

Dr. W.M. Stacey, Fusion Research Center, Georgia Institute of Technology, USA

Dr. J ohn Willis, U.S. Department of Energy, Office of Fusion Energy Sciences, USA

Mr. Paul H. Wright, Indianapolis, Indiana, USA 
The Princeton Plasma Physics Laboratory is operated by Princeton University under contract with the U.S. Department of Energy.

\author{
Information Services \\ Princeton Plasma Physics Laboratory \\ P.O. Box 451 \\ Princeton, NJ 08543
}

Phone: 609-243-2750

Fax: 609-243-2751

e-mail: pppl_info@pppl.gov

Internet Address: http://www.pppl.gov 